\title{
Accessing the Potential of Satellite and Telemetric Data to Evaluate the Influence of the Heat Flux Exchange in the Water Column Mixing and Stratification
}

\author{
Enner Alcântara \\ Department of Cartography, Sao Paulo State University (UNESP), Presidente Prudente, Brazil \\ Email: enner@fct.unesp.br
}

Received August 3, 2012; revised September 1, 2012; accepted October 2, 2012

\begin{abstract}
The objective of this work is to evaluate the feasibility of moderate resolution satellite data estimating the surface heat balance in a tropical hydroelectric reservoir. Each component of the heat flux balance was computed using the MODIS (Moderate Resolution Imaging Spectroradiometer) water surface temperature (WST) level 2, $1 \mathrm{~km}$ nominal resolution data (MOD11L2, version 5) from 2003 to 2008. The consequence of the heat flux exchange in the water column thermal structure is also investigated. The passage of cold front over a region decreases the atmospheric pressure and air temperature, enhancing the relative humidity. The sensible flux presents a small variability but an increase occurs due to a convective turbulence caused by front passage. The latent flux decrease but insufficiently to cause a condensation, just the evaporation decreases. The upwelling events are the responsible to maintain the loss of heat after the cold front passage.
\end{abstract}

Keywords: Thermal Infrared; Heat and Cooling; Mixing; Stratification

\section{Introduction}

Aquatic systems continually respond to climatic conditions (hydro-metrological processes) that vary over broad scales of space and time. The primary control of the seasonal cycle of water temperature at a given location is the seasonal cycle of incoming shortwave radiation. The response of each water body to meteorological conditions is revealed firstly by the thermal structure of the water column [1]. The precise knowledge of reservoir heat flux dynamics is of paramount relevance for hydrobiological and water quality studies as physical control of the biotic structure in reservoirs is even more important than in natural lakes [2].

Thermal infrared remote sensing applied to freshwater ecosystems has aimed to map surface temperatures [3-5], bulk temperatures [6], circulation patterns [7] and to characterize upwelling events [8]. However, the application of thermal infrared images to estimate the net heat flux in tropical hydroelectric reservoirs is scarce.

Besides the power of thermal remote sensing images to study the water surface temperature, the satellite data is only from the upper most layer of the water surface (skin temperature). To see below the surface some authors had used telemetric data collected by an anchored buoy $[9,10]$.
Based on this, the objective of this paper is to estimate the influence of the heat flux exchange between the water surface and the atmosphere in the water column stratification.

\section{Methodology}

\subsection{Study Area}

Our study site is the Itumbiara hydroelectric reservoir $\left(18^{\circ} 25^{\prime} \mathrm{S}, 49^{\circ} 06^{\prime} \mathrm{W}\right)$, located in a region stretched between Minas Gerais and Goiás States (Central Brazil) that was originally covered by tropical grassland savanna, covering an area of approximately $814 \mathrm{~km}^{2}$ and a volume of 17.03 billion $\mathrm{m}^{3}$ (Figure 1).

The climate in the region is characterized by an average precipitation ranging from $2.0 \mathrm{~mm}$ in the dry season (May-September) to $315 \mathrm{~mm}$ in the rainy season (October-April). In the rainy season the wind intensity ranges from 1.6 to $2.0 \mathrm{~m} \cdot \mathrm{s}^{-1}$ and reaches up to $3.0 \mathrm{~m} \cdot \mathrm{s}^{-1}$ in the dry season, with the preferential wind direction from the southeast. The air temperature in the rainy season ranges from $25^{\circ} \mathrm{C}$ to $26.5^{\circ} \mathrm{C}$ dropping to $21^{\circ} \mathrm{C}$ in June as the dry season starts. The relative humidity has a pattern similar to that of the air temperature, but with a small shift in the minimum value towards September (47\%). Moreover, during the rainy season the humidity can reach $80 \%$. 


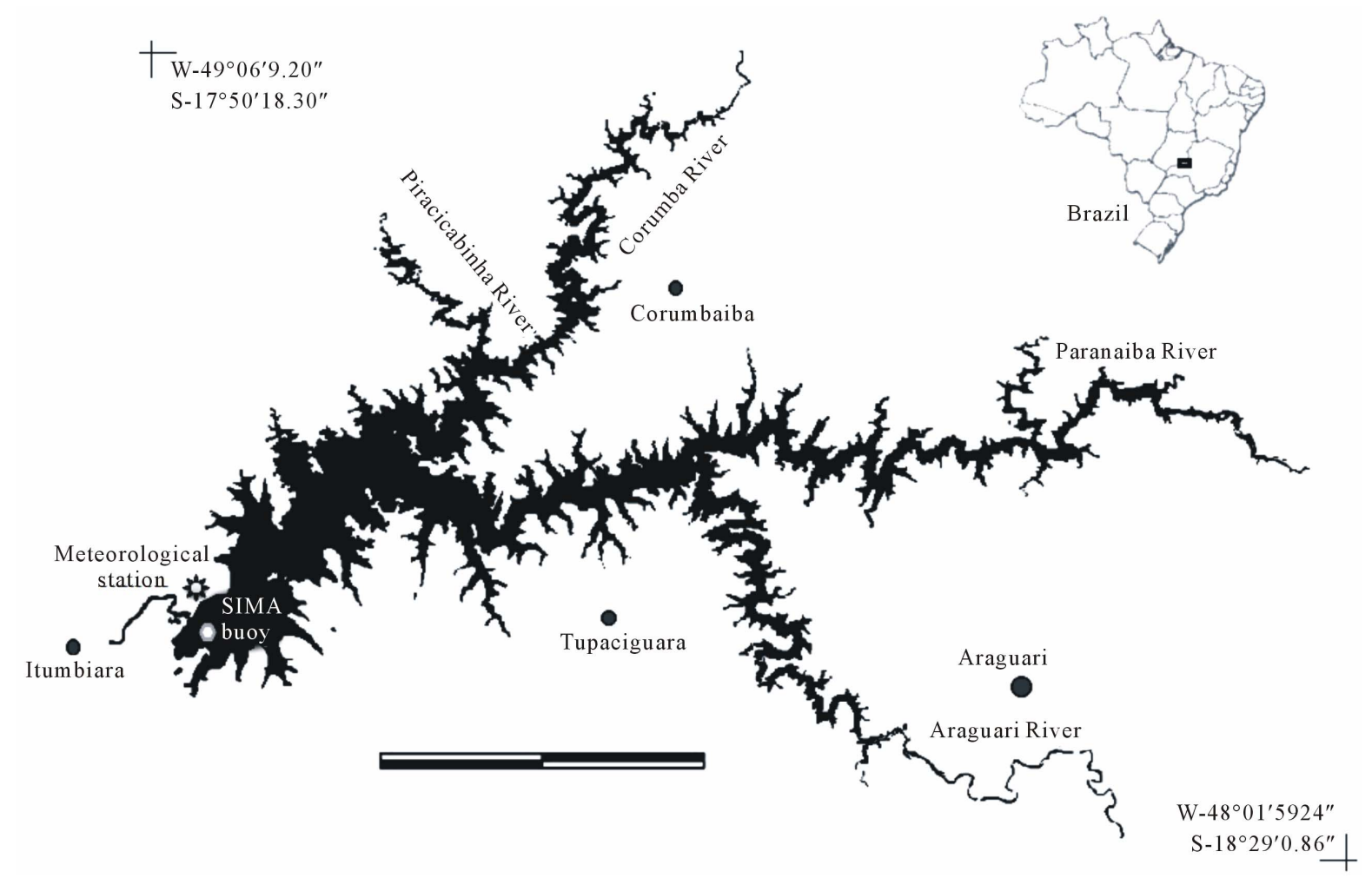

Figure 1. Localization of Itumbiara hydroelectric reservoir in Brazil's central area. Shows the location of the meteorological station and the SIMA buoy.

These hydro-meteorological patterns and the operational routine for energy generation drive the water level fluctuations in the reservoir (Figure 2). The water level rising period starts in December and extends until May ( with a mean period water change of $=0.031 \mathrm{~m} \cdot \mathrm{day}^{-1}$ ); from May to June the water level is high (with a mean period water change of $0.006 \mathrm{~m} \cdot \mathrm{day}^{-1}$ ). Due to the use of water for power generation and evaporation rates, the water level recedes until November (with a mean period water change of $0.032 \mathrm{~m} \cdot \mathrm{day}^{-1}$ ). From November, the water reaches the low level condition until December (with a mean period water change of $0.023 \mathrm{~m} \cdot \mathrm{day}^{-1}$ ).

\subsection{Hydrometeorological Data}

The daily mean air temperature $\left({ }^{\circ} \mathrm{C}\right)$, relative humidity $(\%)$, wind intensity $\left(\mathrm{m}^{-1} \mathrm{~s}^{-1}\right.$ and precipitation $(\mathrm{mm})$ from 2003 to 2008 were used for the study. These data were obtained from a meteorological station near the dam. The daily mean of each variable was converted into monthly means to convert for consistency with the time scale of the satellite data.

\subsection{Buoy Data}

The water temperature at four depths $(5,12,20$ and $40 \mathrm{~m})$ and shortwave radiation was collected by a moored buoy called SIMA (Integrated System for Environmental
Monitoring [11] every hour from 28th March 2009 to 28th February 2010.

SIMA consists of an anchored buoy and its electronics which is instrumented with a suite of meteorological and water quality sensors (see Figure $\mathbf{1}$ for position of SIMA). The SIMA data are collected in preprogrammed time intervals (1 hour) and are transmitted via satellite link in quasi-real time to any user in a range of $2500 \mathrm{~km}$ from the acquisition point.

\subsection{Satellite Data}

MODIS (Moderate Resolution Imaging Spectroradiometer) water surface temperature (WST) level 2, $1 \mathrm{~km}$ nominal resolution data (MOD11L2, version 5) were obtained from the National Aeronautics and Space Administration Land Processes Distributed Active Archive Center [12,13]. All available clear-sky MODIS Terra imagery between 2003 and 2008 were selected by visual inspection, resulting in a total of 786 daytime images and 473 nighttime images (Figure 3 ).

A shoreline mask to isolate land from water was built using the TM-Landsat-5 image in order to isolate any anomalously cold or warm pixels remaining near the shoreline of the reservoir. The WST-MODIS data were extensively validated for inland waters and were considered accurate [3-5]. 

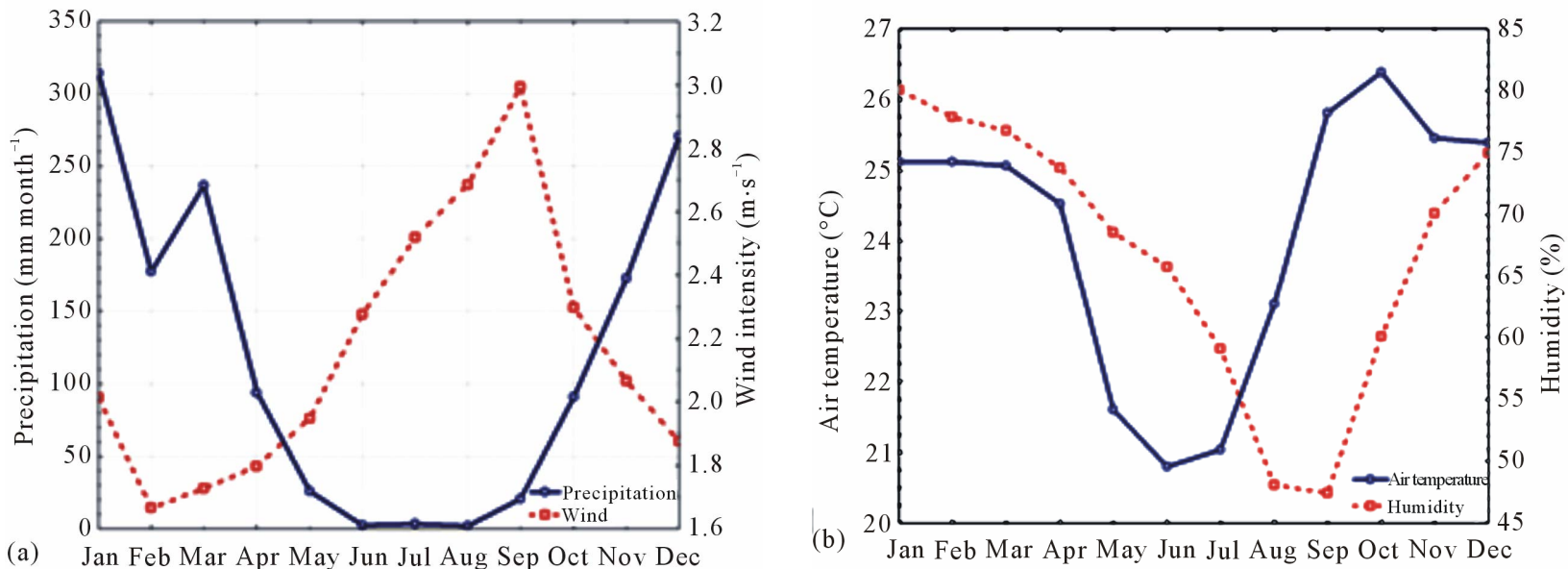

Figure 2. Climate patterns of Itumbiara reservoir: average (2003-2008) monthly mean of (a) precipitation $\left(\mathrm{mm} \cdot \mathrm{month}^{-1}\right)$ and wind intensity $\left(\mathrm{m} \cdot \mathrm{s}^{-1}\right),(\mathrm{b})$ air temperature $\left({ }^{\circ} \mathrm{C}\right)$ and humidity $(\%)$.
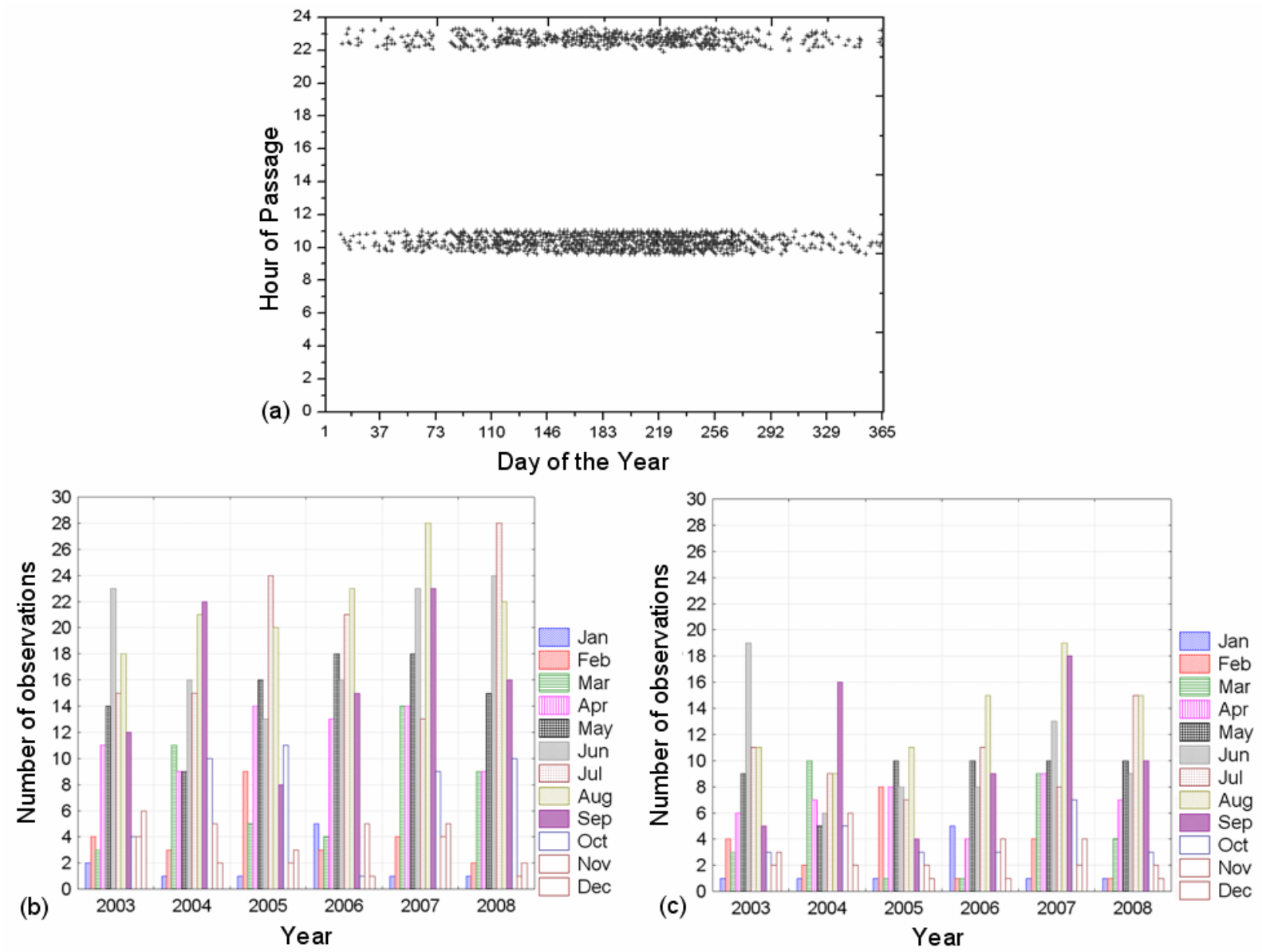

Figure 3. Information about the MODIS thermal infrared images: (a) Hour of passage; (b) Number of satellite imagery available for daytime; (c) Nighttime.

\subsection{Estimating the Heat Balance}

A study of the energy exchange between the lake and atmosphere is essential for understanding the aquatic system behavior and its response to possible changes of environmental and climatic conditions. In aquatic freshwater systems, such as lakes and reservoirs, the heat fluxes are controlled by water surface and atmosphere interactions and are largely affected by the stability of the atmospheric boundary layer (ABL) $[14,15]$. The wind 
intensity, temperature and humidity gradient between water surface and air, short and longwave incoming radiation and air pressure are the main environmental variables related with the heat exchanges. The heat budget in water surface, $\Phi_{\text {tot }}\left(\mathrm{W} \cdot \mathrm{m}^{-2}\right)$, can be summarized as [16]:

$$
\Phi_{\mathrm{tot}}=\Phi_{\mathrm{sw}}\left(1-\alpha_{\mathrm{sw}}\right)+\Phi_{\mathrm{lw}}-\Phi_{\mathrm{rw}}-\Phi_{\mathrm{se}}-\Phi_{\mathrm{le}}
$$

where, $\Phi_{\mathrm{sw}}$ is the shortwave incoming radiation that reach the water surface $\left(\mathrm{W} \cdot \mathrm{m}^{-2}\right), \alpha_{\mathrm{sw}}$ is the water albedo for shortwave radiation, $\Phi_{\mathrm{lw}}$ is the longwave radiation that reach the water surface $\left(\mathrm{W} \cdot \mathrm{m}^{-2}\right), \Phi_{\mathrm{rw}}$ is the longwave radiation emitted by the water surface $\left(\mathrm{W} \cdot \mathrm{m}^{-2}\right)$, $\Phi_{\text {se }}$ is the sensible heat flux $\left(\mathrm{W} \cdot \mathrm{m}^{-2}\right)$ and $\Phi_{\mathrm{le}}$ is the latent heat flux $\left(\mathrm{W} \cdot \mathrm{m}^{-2}\right)$.

The shortwave incoming radiation can be measured directly by radiometer or spectroradiometer and is consider a penetrative term since this sort of radiation can penetrate in the water column following the Beer-Lambert Law [16]. All the other terms of heat budget are considered non penetrative and generally are estimated indirectly (see Equations (2)-(5)) [15,16]:

$$
\Phi_{\mathrm{lw}}=\left(1-\alpha_{\mathrm{lw}}\right)\left(1+0.17 C^{2}\right) \varepsilon_{a} \sigma T_{a}^{4}
$$

where, $\alpha_{\mathrm{lw}}$ is the water albedo for longwave radiation, $C$ is the cloud cover (fraction), $\varepsilon_{a}$ is the air emissivity (dimensionless), $\sigma$ is the Stefan-Boltzmann Constant $\left(5.699 \times 10^{-8} \mathrm{~W} \cdot \mathrm{m}^{-2} \cdot \mathrm{K}^{-4}\right)$ and $T_{a}$ is the air temperature ( $\left.{ }^{\circ} \mathrm{C}\right)$.

$$
\Phi_{r w}=\varepsilon_{w} \sigma T_{w}^{4}
$$

where, $\varepsilon_{w}$ is the water emissivity (dimensionless) and $T_{w}$ is the water surface temperature $\left({ }^{\circ} \mathrm{C}\right)$.

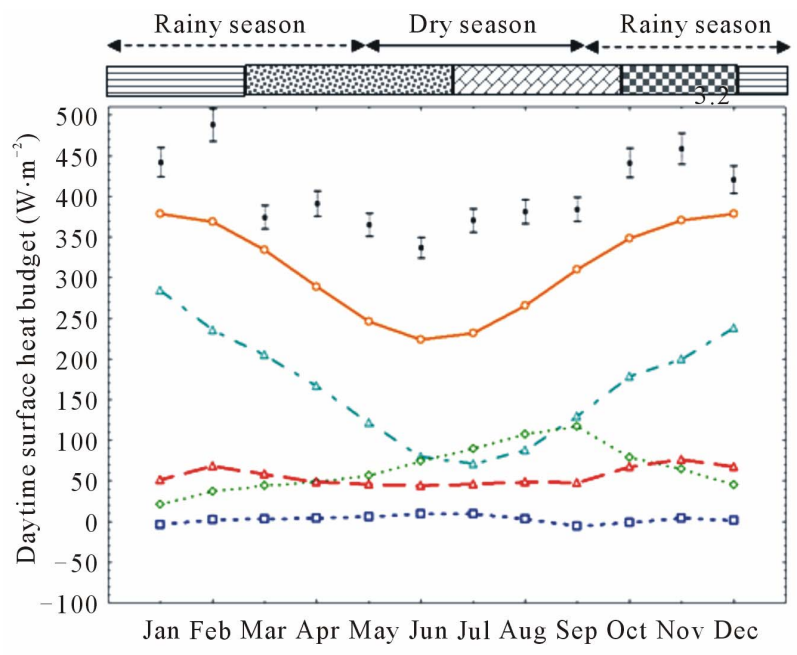

(a) I Measured SW $\multimap-$ Estimated SW - $\mathrm{S}$ - Sensible Summer Autumn

$$
\begin{aligned}
& \Phi_{\mathrm{se}}=\rho_{a} U_{10} C_{a} C_{H}\left(T_{a}-T_{w}\right) \\
& \Phi_{\mathrm{le}}=\rho_{a} U_{10} L_{V} C_{E}\left(e_{a}-e_{w}\right) 0.622 p^{-1}
\end{aligned}
$$

where $\rho_{a}$ is the air density $\left(\mathrm{kg} \cdot \mathrm{m}^{-3}\right), U_{10}$ is wind speed at 10 meters above the water surface $\left(\mathrm{m}^{\cdot} \mathrm{s}^{-1}\right), C_{a}$ is specific heat of air $\left(1003 \mathrm{~J} \cdot \mathrm{kg}^{-1} \cdot \mathrm{K}^{-1}\right), L_{V}$ is latent heat of vaporization $\left(\mathrm{J} \cdot \mathrm{kg}^{-1}\right), e_{a}$ is vapor pressure (mbar), $e_{w}$ is saturated vapor pressure at $T_{w}$ (mbar), $p$ is the atmospheric pressure (mbar) and $C_{H}$ and $C_{E}$ are the bulk coefficients for sensible and latent heat transfer respectively (dimensionless).

Due to the complexity of these fluxes and the limitations of the atmospheric data available for the area of study, some constraints were imposed. The air temperature $\left(T_{a}\right)$ and wind intensity $(|\boldsymbol{V}|)$ were considered the same for the whole reservoir because only one meteorological station was available. Other constraint is that this heat flux balance is due two periods of a day, that is, daytime (10:30 h) and nighttime (23:30 h).

\section{Results and Discussion}

The estimated annual cycle of heat fluxes is shown in Figure 4. It gives the spatially-averaged monthly mean of reservoir using meteorological and satellite time series data of the six years (from 2003 to 2008).

The incoming shortwave radiation is the term with largest contribution to the heat balance. To obtain the relative error of our estimated shortwave radiation we used the measured (Novalynx sensor, accuracy $\pm 5 \%$ ) shortwave by SIMA buoy covering the period from $1^{\text {st }}$ March 2009 to $28^{\text {th }}$ February 2010 (Figure 4(a)).

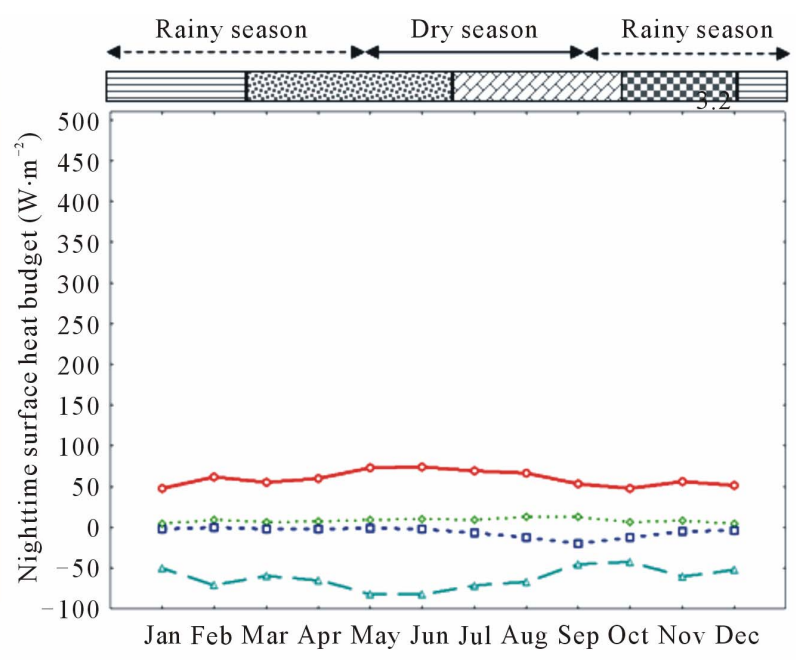

$\sim \diamond$. Latent $\quad-\Delta-$ Longwave $-\Delta-$ Net radiation

(b)

B) Spring

Figure 4. Energy budget components for (a) Daytime (10:30 h) and (b) Nighttime (23:30 h). SW is the shortwave radiation. 
The RMSE in shortwave radiation showed here affects mainly the surface heat flux balance ( $\Phi_{\text {tot }}$, because the longwave radiation and the sensible heat flux are mainly driven by the difference between air and water temperature, and the latent flux by wind intensity. Based on this the expected error in $\Phi_{\text {tot }}$ is on average $10 \%$ higher than was observed (Figure 4(a)).

The measured shortwave radiation by a radiometer mounted in a buoy in the sea presents also an error from 6.4 to $11.3 \mathrm{Wm}^{-2}$ (if the mast is in the vertical or tilted $15^{\circ}$, respectively).

\subsection{Latent Heat Flux}

The latent heat flux was positive, corresponding to a heat gain in all months during daytime and nighttime. The nighttime computation was set at 23:30 h, and at this time, the water surface did not lose all the heat gained during daytime. From January to June (summer to autumn), the latent flux was near zero for both daytime and nighttime. From August to October (winter to spring), the latent flux during daytime was more pronounced than that of nighttime because of the high temperature amplitude.

This amplitude occurs because of the formation of fog just above the surface, which warms the water by precipitating into it, as observed in Figure 4(a) (mainly at the beginning of the rainy season in September). The positive latent flux generally occurs when the atmosphere above the water is stable, with little turbulent mixing in the atmospheric boundary layer [17]. From November to December, the latent flux decreases again, and the cycle recommences.

\subsection{Sensible Heat Flux}

A negative sensible heat flux occurs when the surface loses heat by convective and advective processes and is positive when the surface gains heat. For daytime, the sensible heat flux was only negative in January (summer), indicating that the water surface was colder than in December and February. It was positive for the others months (see Figure 4(a)). A typical case of a heat gain in the sensible flux occurred in October (spring), when this variable reached its highest value $\left(15.01 \mathrm{~W} \cdot \mathrm{m}^{-2}\right)$ and when the water surface temperature reached its highest value. For nighttime, the sensible flux was negative for all months of the year with a peak in September $(-20.37$ $\mathrm{W} \cdot \mathrm{m}^{-2}$ ) which can be related to advection caused by by relatively high wind intensity $\left(3.1 \mathrm{~m} \cdot \mathrm{s}^{-1}\right)$. The lowest flux occurred in February $\left(-0.14 \mathrm{~W} \cdot \mathrm{m}^{-2}\right)$, when the wind intensity was two times lower than in September (1.7 $\left.\mathrm{m} \cdot \mathrm{s}^{-1}\right)$. This pattern of sensible heat distribution over time was also observed by [18] in a reservoir in Spain.

\subsection{Net Longwave Radiation}

The net longwave radiation as computed by equation 3 expresses the net balance between outgoing long-wave radiation from the lake and incoming long-wave radiation from the atmosphere. Positive values indicate a loss of energy by the reservoir. The more contrast there is between the water and air temperature, the larger the flux is. Net longwave radiation consists of a loss of energy throughout the year at daytime and nighttime. Losses are greater during daytime because the difference between the lake and atmosphere temperatures decreases. Their seasonal patterns differ slightly.

Daytime longwave radiation increases from March to August with a maximum value of $110 \mathrm{~W} \cdot \mathrm{m}^{-2}$ and decreases until January with a minimum value of about 50 $\mathrm{W} \cdot \mathrm{m}^{-2}$. Nighttime longwave radiation increases from March until June with a maximum value of about 74 $\mathrm{W} \cdot \mathrm{m}^{-2}$ and decreases until October with a value of about $48 \mathrm{~W} \cdot \mathrm{m}^{-2}$. It then increases again slightly in November and December and diminishes in January, reaching similar values as those in October.

The contrast between daytime and nighttime values is at its greatest in September $\left(53 \mathrm{~W} \cdot \mathrm{m}^{-2}\right)$ and at its lowest in January $\left(3 \mathrm{~W} \cdot \mathrm{m}^{-2}\right)$. During daytime, long-wave values are higher from May $\left(95.94 \mathrm{~W} \cdot \mathrm{m}^{-2}\right)$ to September $\left(106.36 \mathrm{~W} \cdot \mathrm{m}^{-2}\right)$ than from January $\left(51.28 \mathrm{~W} \cdot \mathrm{m}^{-2}\right)$ to April $\left(78.56 \mathrm{~W} \cdot \mathrm{m}^{-2}\right)$ and October $\left(96.12 \mathrm{~W} \cdot \mathrm{m}^{-2}\right)$ to December $\left(84.14 \mathrm{~W} \cdot \mathrm{m}^{-2}\right)$. The period of high flux of longwave radiation occurs during autumn-winter in the dry season, that is, when the cloud cover is very low. The lowest values occur in the rainy season with high cloud cover (spring-summer).

\subsection{Net Flux}

The net heat flux during nighttime always corresponded to a loss of energy from the lake (negative values) because the short wave radiation stopped. The daytime flux is always positive, corresponding to a source of energy. This is because loss terms (back longwave radiation, sensible heat flux and latent heat flux) do not counterbalance the source terms (shortwave and atmospheric longwave radiation).

The daytime net radiation and heat flux followed a nearly similar seasonal pattern as the shortwave radiation. It had a maximum around $300 \mathrm{~W} \cdot \mathrm{m}^{-2}$ during January. It steadily decreased until June, with a value of about 60 $\mathrm{W} \cdot \mathrm{m}^{-2}$. It remained with low values (less than 100 $\mathrm{W} \cdot \mathrm{m}^{-2}$ ) until August and then increased steadily until December. The nighttime net heat and radiation flux also followed a seasonal pattern, with absolute maximum values occurring from June until August and lowest absolute values during summer. The daytime heat flux was always that of nighttime, except in June and July. The 
balance between daytime and nighttime followed a seasonal pattern with higher positive values during summer, steadily decreasing during autumn until reaching negative values in winter. It then increases steadily again (Figure 4). This seasonal pattern conforms to the water surface temperature variation along the year.

When we proceed with a balance between the daytime heat budget (Figure 4(a)) and nighttime heat budget (Figure 4(b)), we have the effective (diurnal) heat budget (Figure 5). The effective heat budget shows that during the rainy season the reservoir gains heat, and it loses heat during dry season. This pattern is due to the incoming shortwave radiation (see Figure 4(a)), which, during the day, adds heat to the water column and at night loses heat due to convective cooling.

For January, February and April the northwest section of the reservoir gains more heat than the southeast section. This is because the dominant wind direction is from southeast to northwest as the wind drives the warm masses into the littoral zone by advection. For March, the southwest heats more than the northeast. During May, the greatest area of the reservoir loses heat, and only a small area in the main body of the reservoir gains heat. From June to July, heat loss dominates the whole reservoir, and the northwest losses are lower than the southeast losses. From August to December, the reservoir heats from the littoral zone to the center of the reservoir; but in October, it presents the greatest heat gradient between the littoral zone and the center of the reservoir.

\subsection{The Water Column Response}

The primary effect of the surface heat balance pattern is perceptible in the thermal structure of the water column. The Figure 6 shows that during the months when the heat balance are positive (heat gain) the water columns stratify; and when the heat balance are negative the water column exhibits mixing. The main effect of this differential heat and cooling of the water in the reservoir is on the water quality. Iron and manganese, due to circulation and mixing, can be released after a period of reducing conditions in the bottom, promoted by the stratification, resulting in increased costs of water treatment for drinking purposes [19].

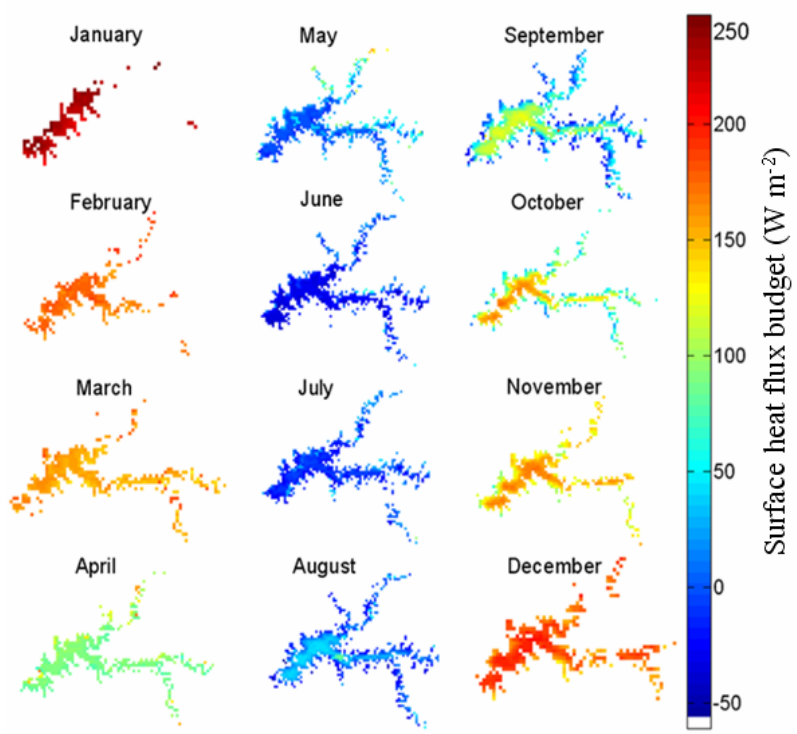

Figure 5. Spatially surface heat flux balance $\left(\mathrm{W} \cdot \mathrm{m}^{-2}\right)$ over the Itumbiara reservoir.

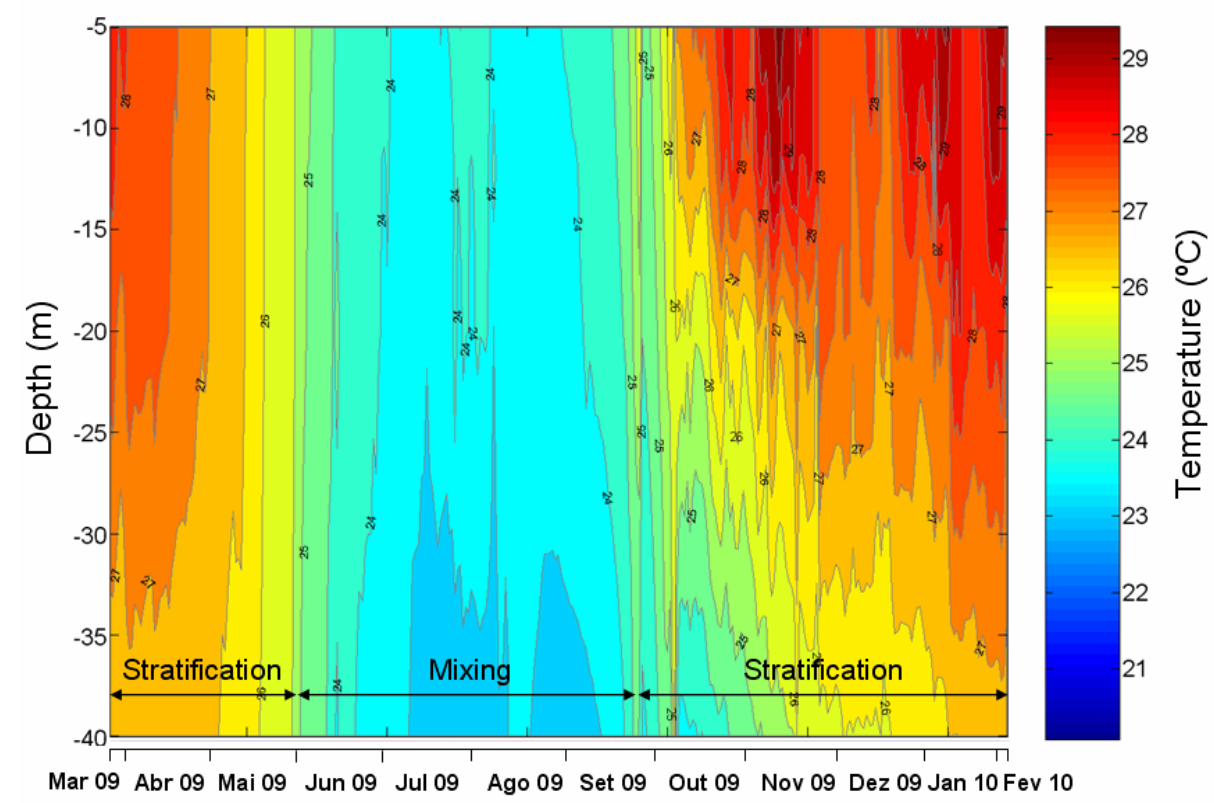

Figure 6. Thermal structure of the Itumbiara reservoir. 
Also during the mixing period the events of upwelling events can occur, bringing nutrient-rich waters to the surface. If prolonged, the upwelling events could induce the growth of algae in tropical reservoirs in Brazil.

\subsection{The Effect of Cold Front Passage during Dry Season}

From Figure 6 is clear that during the low shortwave radiation, low air temperature the water can mix. However, the cold front passage over the reservoir can increase the possibility to occur the overturn events.

In a research conducted to check the side effects of cold fronts passage in the Itumbiara reservoir, the authors [10] had showed that during this meteorological event the water can losses from 81.57 to $569 \mathrm{cal} \cdot \mathrm{cm}^{-2}$ in first six days after the passage. This heat content modification due to the cold front will reflect in the water column temperature and stability (Figure 7(a)). Before the passage of the front the water column presented a little temperature difference between the epilimnion and metalimnion; with the passage of the cold front the water temperature of the top-most layer decrease and the difference of temperature in the water column decreases also.

To indicate the degree of stability and mixing in the reservoir, due to the passage of cold front, the $L_{N}$ was used [15]. The $L_{N}$ characterizes the dynamic stability of a lake and is a ration of moments about the center of lake volume of the wind force at the surface of the lake and the gravity restoring force to the stratification.

$$
L_{N}=\frac{g S_{t}\left(1-\frac{z_{T}}{H}\right)}{\rho u_{*} A^{1.5}\left(1-\frac{z_{g}}{H}\right)},
$$

where $\mathrm{g}$ is gravity, $\rho$ is the density of water, $z_{T}$ is the height to the center of the metalimnion, $z_{g}$ is the height to the center of volume of the lake, $A$ is lake area, $H$ is the depth of the lake, $u_{*}$ is the friction velocity in water and $S_{t}\left(\mathrm{gcm}^{-1} \mathrm{~cm}^{-2}\right)$ is an estimate of the stability of the reservoir calculated as [20]:

$$
S_{t}=\int_{0}^{z m}\left(z-z_{g}\right) A(z) \rho(z) d z
$$

where $z_{g}$ can be obtained as:

$$
z g=\frac{\int_{0}^{z m} z A(z) d z}{\int_{0}^{z m} A(z) d z}
$$

The analysis of Lake Number $\left(L_{N}\right)$ are show in Figure 7(b). When $L_{N}>1$ there is no deep upwelling and when $L_{N}<1$ the cold deep, often nutrient rich, water from the hypolimnion will reach the surface layer during the wind episode [21].

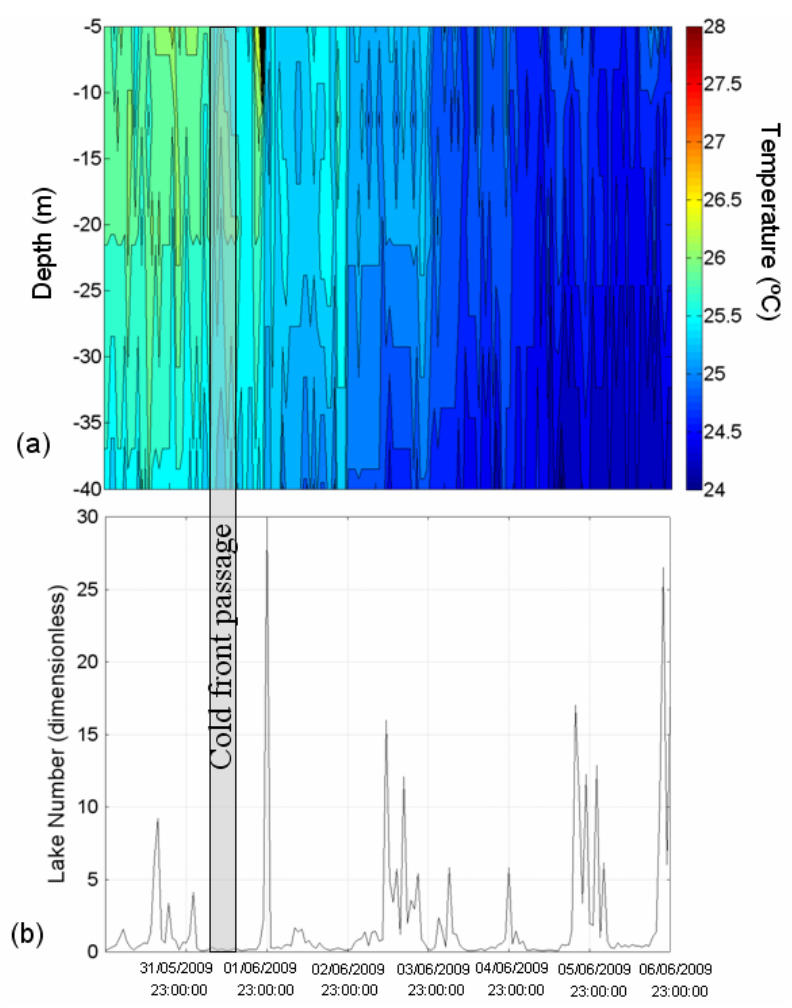

Figure 7. Thermal structure (a) and the lake number- $\boldsymbol{L}_{N}$ (b) for the Itumbiara reservoir.

For $L_{N}$ as high as 60 , little turbulent mixing is expected in the hypolimnion [22]. In this case all $L_{N}>1$ occurred during the daytime when the incident shortwave radiation is present, but after the passage of the cold front the values of $L_{N}$ increase during the heating phase. Often $L_{N}<1$ occurred during the nighttimes, the unique exception is the day during the cold passage with $L_{N}$ less than 1.

After the passage of the front the water from hypo- liminion progressively cooler and the mixed layer goes up to the top layer. The fact of the $L_{N}$ increases after the front passage during the daytime could be explained by the fact that during the cold front passage the water losses energy to the atmosphere and when the cold front dissipate the incident shortwave radiation heats the surface creating the condition enhancing the stability of the water column.

\section{Conclusions}

The use of satellite data to estimate the heat balance is useful and facilitates more accurate analysis of the physical processes in the whole surface water. With these results it is important to consider the predictive capacity of the combined use of satellite, meteorological and in situ temperature data to study the interactions between the surface water and the surrounding atmosphere. 
The passage of cold front over a region decreases the atmospheric pressure and air temperature, enhancing the relative humidity. With the formation of cloud cover the longwave radiation increase and transfer heat by turbulent convection to the water surface. The sensible flux presents a small variability but an increase occurs due to a convective turbulence caused by front passage; in other hand the latent flux decrease but insufficiently to cause a condensation, just the evaporation decreases. The upwelling events are the responsible to maintain the loss of heat after the cold front passage.

There is a high dependency of water column stability to the climate and increase the knowledge about atmospheric events in these systems can help in the water resources management.

\section{Acknowledgements}

The authors would like to thank the FAPESP Project 2007/08103-2, INCT for Climate Change project (grant 573797/2008-0 CNPq). Enner Alcântara thanks CAPES grant 0258059 .

\section{REFERENCES}

[1] W. Ambrosetti, L. Barbanti and N. Sala, "Residence Time and Physical Processes in Lakes,” Journal of Limnology, Vol. 63, No. 1, 2002, pp. 1-15.

[2] D. Uhlmann, "Reservoirs as Ecosystems," International Review of Hydrobiology, Vol. 83, 1998, pp. 13-20.

[3] D. Oesch, J.-M. Jaquet, R. Klaus and P. Schenker, "Multi-Scale Thermal Pattern Monitoring of a Large Lake (Lake Geneva) Using a Multi-Sensor Approach,” International Journal of Remote Sensing, Vol. 29, 2008, pp. 5785-5808. doi:10.1080/01431160802132786

[4] A. Reinart and M. Reinhold, "Mapping Surface Temperature in Large Lakes with MODIS Data," Remote Sensing of Environment, Vol. 112, No. 2, 2008, pp. 603-611. doi:10.1016/j.rse.2007.05.015

[5] E. T. Crosman and J. D. Horel, "MODIS-Derived Surface Temperature of the Great Salt Lake,” Remote Sensing of Environment, Vol. 113, No. 1, 2009, pp. 73-81. doi:10.1016/j.rse.2008.08.013

[6] S. Thiemann and H. Schiller, "Determination of the Bulk Temperature from NOAA/AVHRR Satellite Data in a Midlatitude Lake," International Journal of Applied Earth Observation and Geoinformation, Vol. 4, No. 4, 2003, pp. 339-349. doi:10.1016/S0303-2434(03)00021-7

[7] S. G. Schladow, S. O. Palmarsson, T. E. Steissberg, S. J. Hook and F. J. Prata, "An Extraordinary Upwelling Event in a Deep Thermally Stratified Lake,” Geophysical Research Letters, Vol. 31, 2004, pp. 1-4.

[8] T. E. Steissberg, S. J. Hook and S. G. Schladow, "Characterizing Partial Upwellings and Surface Circulation at Lake Tahoe, California-Nevada, USA with Thermal Infrared Images,” Remote Sensing of Environment, Vol. 99, No. 1-2, 2005, pp. 2-15.
[9] E. Alcântara, E. Novo, J. Stech, J. Lorenzzetti, C. Barbosa, A. Assireu and A. Souza, "A Contribution to Understanding the Turbidity Behavior in an Amazon Floodplain,” Hydrology and Earth System Science, Vol. 14, 2010, pp. 351-364. doi:10.5194/hess-14-351-2010

[10] E. Alcântara, M.-P. Bonnet, A. T. Assireu, J. L. Stech, E. M. L. M. Novo and J. Lorenzzetti, "On the Water Thermal Response to the Passage of Cold Fronts: Initial Results for Itumbiara Reservoir (Brazil)," Hydrology and Earth System Sciences Discussions, Vol. 7, No. 6, 2010, pp. 9437-9465. doi:10.5194/hessd-7-9437-2010

[11] J. L. Stech, I. B. T. Lima, E. M. L. M. Novo, C. M. Silva, A. T. Assireu, J. A. Lorenzzetti, J. C. Carvalho, C. C. F. Barbosa and R. R. Rosa, "Telemetric Monitoring System for Meteorological and Limnological Data Acquisition," International Association of Theoretical and Applied Limnology, Vol. 29, No. 4, 2006, pp. 747-1750.

[12] Z. Wan, "New Refinements and Validation of the MODIS Land-Surface Temperature/Emissivity Products,” Remote Sensing of Environment, Vol. 112, No. 1, 2008, pp. 59-74. doi:10.1016/j.rse.2006.06.026

[13] C. C. Justice, et al., "The Moderate Resolution Imaging Spectroradiometer (MODIS): Land Remote Sensing for Global Change Research,” IEEE Transactions on Geoscience and Remote Sensing, Vol. 36, No. 4, 1998, pp. 1228-1247. doi:10.1109/36.701075

[14] P. Verburg and J. P. Antenucci, "Persistent Unstable Atmospheric Boundary Layer Enhances Sensible and Latent Heat Loss in a Tropical Great Lake: Lake Tanganyika,” Journal of Geophysical Research, Vol. 115, 2010, pp. 113.

[15] J. Imberger and J. J. C. Patterson, "Physical Limnology," Advances in Applied Mechanics, Vol. 27, 1990, pp. 303475. doi:10.1016/S0065-2156(08)70199-6

[16] M.-P. Bonnet, M. Poulin and J. Devaux, "Numerical Modeling of Thermal Stratification in a Lake Reservoir: Methodology and Case Study,” Aquatic Sciences, Vol. 62, No. 2, 2000, pp. 105-124. doi:10.1007/s000270050001

[17] B. Lofgren and Y. Zhu, "Surface Energy Fluxes on the Great Lakes Based on Satellite-Observed Surface Temperatures 1992 to 1995," Journal of Great Lakes Research, Vol. 26, No. 3, 2000, pp. 305-314. doi:10.1016/S0380-1330(00)70694-0

[18] T. Serra, J. Vidal, X. Casamitjana, M. Soler and J. Colomer, "The Role of Surface Vertical Mixing in Phytoplankton Distribution in a Stratified Reservoir," Limnology and Oceanography, Vol. 52, No. 2, 2007, pp. 620634. doi:10.4319/lo.2007.52.2.0620

[19] J. G. Tundisi, T. Matsumura-Tundisi, J. D. Arantes Junior, J. E. M. Tundisi, N. F. Manzini and R. Ducrot, "The Response of Carlos Botelho (Lobo, Broa) Reservoir to the Passage of Cold Fronts as Reflected by Physical, Chemical and Biological Variables,” Brazilian Journal of Biology, Vol. 64, No. 1, 2004, pp. 177-186. doi:10.1590/S1519-69842004000100020

[20] G. E. Hutchinson, “A Treatise on Limnology, Geography, Physics and Chemistry,” John Wiley, New York, 1957, 1015 p.

[21] J. Antenucci and J. Imberger, “The Seasonal Evolution of 
Wind/Internal Wave Resonance in Lake Kinneret," Limnology and Oceanography, Vol. 48, No. 5, 2003, pp. 2055-2061. doi:10.4319/lo.2003.48.5.2055
[22] M. Hondzo and H. G. Stefan, "Long-Term Water Quality Predictors,” Water Research, Vol. 30, No. 12, 1996, pp. 2835-2852. doi:10.1016/0043-1354(95)00286-3 